\title{
FORMULATION, IN-VITRO AND EX-VIVO \\ CHARACTERIZATION OF ROPINIROLE HYDROCHLORIDE BUCCAL MUCOADHESIVE FILMS \\ BY
}

\author{
Nadia M. Moursi ${ }^{1}$, Ahmed H. Elshafeey ${ }^{1}$, Manal Y. Hamza ${ }^{2}$, Rehab M. M. Elhadidy ${ }^{2}$, \\ FROM \\ 'Department of Pharmaceutics and Industrial Pharmacy, Faculty of Pharmacy, Cairo \\ University, Cairo, Egypt. \\ ${ }^{2}$ National Organization for Drug Control and Research, Cairo, Egypt.
}

\begin{abstract}
Ropinirole Hydrochloride ( $\mathrm{RHCl}$ ) is one of the most important highly selective Dopamine agonist drugs for the treatment of Parkinson's disease (PD). The aim of the present study is to develop buccoadhesive films of $\mathrm{RHCl}$ to overcome the first pass hepatic metabolism of the drug which is the cause for its low bioavailability (50-55\%) and to achieve the greater therapeutic efficacy. Buccal films of $\mathrm{RHCl}$ were prepared by the solvent casting method using the hydrophilic mucoadhesive polymer chitosan as the base matrix at different concentrations (1\& $1.5 \% \mathrm{w} / \mathrm{v})$. Polyvinyl pyrrolidone (PVP) $\mathrm{K} 25 \& \mathrm{~K} 30$ at different concentrations $(0.035 \& 0.07 \mathrm{gm})$ were incorporated into the films to modify $\mathrm{RHCl}$ release rate from formulation. Compatibility studies of drug and polymers were performed by DSC and FTIR spectroscopy. In-vitro and ex-vivo characterization was done as well as stability study. A $2^{4}$ full factorial design was employed to study the effect of independent variables on ex-vivo mucoadhesive strength, ex-vivo residence time and in-vitro drug release. Results showed the absence of incompatability between the drug and chosen polymers. Prepared Mucoadhesive films were clear, flexible, with good folding endurance, uniform in weight, thickness, drug content and stable either in human saliva for 6 hours or at ambient temperature for 1 year. Formula F4 (1 \% w/v chitosan, PVP K25, PEG 400) was the optimal bucoadhesive film having the highest percentage drug release $(95.25 \%)$ with high stability.
\end{abstract}

\section{INTRODUCTION}

Drug delivery systems through mouth transmucosal routes offer novel routes of drug administration and provide a direct entry of drug into systemic circulation to the targeted site in the body. Thus, avoiding hepatic first pass effect improves bioavailability of drugs with low peroral bioavailability. Oral transmucosal drug delivery can be achieved through 1 of the 3 types of oral mucosa: sublingual, gingival, and the most advantageous buccal mucosa (Junginge et al., 1999).

Recently, drug delivery systems via buccal mucosa by using bioadhesive polymers in the form of tablets, disks, films, patches, strips, gels and ointments have been developed. Buccoadhesive drug delivery system has a potential effect on improving therapeutic efficacy of drugs through increasing the residence time of the dosage form at the site of absorption (Haris and Robinson, 1992, Bruschi and Freitas, 2005). It is suitable for drugs either presystemic metabolised or unstable in the 
acidic environment associated with peroral administration. It provides the ease of administration and termination of drug delivery when required (Rathbone et al., 1994). An ideal buccal adhesive system must maintain its position in the mouth for few hours, releases the drug in a controlled pattern, and provides drug release in a unidirectional way towards the mucosa (Lopez et al., 1998).

However, buccal films are more attractive than other buccal forms with greater flexibility and larger surface area than mucoadhesive tablets and with higher residence time than gels and ointments (Anders and Merkle, 1989). An ideal buccal film should be strong and elastic at the same time to withstand stress from activities in the mouth. The swelling, mechanical and mucoadhesive properties of buccal films are critical and must be evaluated for increasing residence time which will increase formulation efficacy. Also, films can provide comfort and improved patient compliance due to their small size and reduced thickness, comparative to tablets and lozenges (Morales and McConville, 2010).

Ropinirole Hydrochloride is highly selective non-ergoline D2/D3 Dopamine agonist indicated for the treatment of symptoms and signs of Idiopathic Parkinson's disease (PD) (Hobson et al., 1999): . RHCl was the first medication approved by the US Food and Drug Administration (FDA) for the treatment of moderate-to-severe primary restless legs syndrome (RLS) (Kushida, 2006).

Although RHCL is well absorbed after peroral administration reaching peak plasma concentration at 1.5 hours (Boothman and Spokes, 1990), its bioavailability is low $(50 \%)$ due to the extensive first-pass effect (Dollery, 1999). Its' mean elimination half-life is about 6 hours $\left(t_{1 / 2}=6\right.$ hrs) (Kaye and Nicholls, 2000). Moreover, it is a potent photosensitive drug (low dose $0.25-5 \mathrm{mg}$ ) with low molecular weight (MW 260), sufficiently lipophilic ( $\log P=3.32$ ) (Azeem et al., 2009). So, it is obvious that RHCL is a suitable candidate for buccal route administration.

The purpose of this study is to develop mucoadhesive buccal films of RHCL using the mucoadhesive polymer chitosan as a matrix polymer and polyvinyl pyrrolidone (PVP) K25 \& K30. A $2^{4}$ full factorial design was employed to study the effect of the independent variables on dependent variables like swelling index, ex-vivo mucoadhesive strength and residence time and finally on in- vitro drug release.

\section{MATERIALS AND METHODS}

\section{Materials}

Ropinirole Hydrochloride (99.96\% purity) was kindly supplied from Eva Pharma Pharmaceuticals Co., Egypt. Chitosan, (> 85\% deacetylated), molecular weight (100000-300000), Sodium Carboxymethyl Cellulose, Hydroxypropyl Methyl Cellulose, Acetonitrile (HPLC grade), Potassium Bromide (IR grade) were purchased from SigmaAldrich Co., St. Louis, USA. Polyvinyl pyrrolidone (PVP) K25 \& K30, Polyethylene glycol (PEG) 400 \& ethyl cellulose were purchased from Fluka Biochemica Co., Switzerland. Glycerin, Propylene glycol, Glacial acetic acid, Hydrochloric acid, Sodium Chloride, Potassium dihydrogen Phosphate \& Disodium hydrogen Phosphate were purchased from EL-Nasr Co., Egypt. Spectra/Pore ${ }^{\odot}$ dialysis membrane 12,000-14,000 molecular weight cut off was purchased from Spectrum Laboratories Inc., USA. 


\section{Methods}

\section{Preliminary Study for Ropinirole Hydrochloride Buccal Mucoadhesive Chitosan Films}

The successful formulation of a stable and effective solid dosage form depends on the careful selection of the excipients. During the primary formulation trials, different types of mucoadhesive polymers with different concentrations were tested in preparing chitosan buccal films to select the types and the concentrations of polymers to be used in the full factorial design stage. The types of polymers used were sodium carboxymethyl cellulose, hydroxypropyl methyl cellulose, PVPK25 and PVPK30 in concentrations of $0.5,1,1.5$ and $2 \%$. Chitosan was prepared using $1 \%, 1.5 \%$ and $2 \%$ $\mathrm{v} / \mathrm{v}$ of glacial acetic acid and $0.1 \mathrm{~N}$ Hydrochloric acid. All were tested to select the system which gives easily pealed flexible films.

Then, three types of plasticizers were screened namely glycerin, propylene glycol and PEG 400 to prepare elastic films with improved mechanical properties. Plasticizers were used at concentrations of $0.1 \mathrm{gm}, 0.15 \mathrm{gm}$ and $0.2 \mathrm{gm}$. For screening of different plasticizers, $1.5 \% \mathrm{w} / \mathrm{v}$ chitosan films were prepared using $1 \%$ glacial acetic acid as solvent.

\section{Physicochemical Compatibility Study}

DSC and FTIR analysis were used for the evaluation of possible interactions that could occur between RHCL and the chosen polymers after the primary formulation trials. Analysis were carried out for the pure drug $\mathrm{RHCl}$, for each used polymer (Chitosan, PVPK25, PVPK30) as well as for the drug- polymer physical mixture in the ratio $(1: 1 \mathrm{w} / \mathrm{w})$ prepared by simple mixing of ingredient on a clean waxy paper.

\section{A. Differential Scanning Calorimetric (DSC) Study}

The DSC patterns were measured using a Shimadzu DSC device at a scanning rate of $10{ }^{\circ} \mathrm{C} / \mathrm{min}$ from $50{ }^{\circ} \mathrm{C}$ to $400{ }^{\circ} \mathrm{C}$ under nitrogen gas stream at a flow rate of 40 $\mathrm{ml} / \mathrm{min}$. Samples of 4-8 $\mathrm{mg}$ were accurately weighed and encapsulated into flat bottomed aluminum pans with crimps-on lids. The instrument was calibrated with indium as a standard. Analysis was carried out using DSC apparatus (Shimadzu SC-60, Japan) (Chandiran and Anandakirouchenane, 2014).

\section{B. Fourier Transform Infrared (FTIR) Study}

Samples of 4-8 mg were mixed with Potassium Bromide (IR grade) in a ratio of 1: 99, compressed into disks under vacuum. The disks were scanned from 4000 to 500 $\mathrm{cm}^{-1}$ at a resolution of $1 \mathrm{~cm}^{-1}$ with an empty pellet holder as a reference and were analyzed using IR spectrophotometer (Maltson, Genesis II FTIR, USA) (Chandra et al., 2015).

\section{Preparation of Ropinirole Hydrochloride Buccal Mucoadhesive Chitosan Films:}

\section{A. Factorial Design for the Optimization of the Prepared Buccal Films}

Factorial design is a very essential statistical tool to understand the complexity of pharmaceutical formulations (Mishra and Amin, 2009). Based on the results of primary formulation trials, a full factorial design was built up for further optimization of the prepared buccal films. Using Design Expert ${ }^{\circledR}$ version 7 software, a $2^{4}$ full factorial 
model was developed to study the main effects and interactions of four factors namely: the concentration of chitosan $\left(\mathbf{X}_{1}\right)$ and the type of mucoadhesive polymer added $\left(\mathbf{X}_{2}\right)$, the added mucoadhesive polymer concentration $\left(\mathbf{X}_{\mathbf{3}}\right)$ and the type of plasticizer $\left(\mathbf{X}_{\mathbf{4}}\right)$ as shown in table (1).

Table (1): The independent variables of a $2^{4}$ full factorial design for optimization of RHCL buccal films.

\begin{tabular}{lrc}
\hline Factors $\quad$ Independent Variables) & \multicolumn{2}{c}{ Levels } \\
\hline $\mathbf{X}_{\mathbf{1}}:$ concentration of Chitosan $(\%)$ & $1 \%$ & $1.5 \%$ \\
\hline $\mathbf{X}_{\mathbf{2}}$ : Added mucoadhesive polymer Type & PVPK25 & PVPK 30 \\
\hline $\mathbf{X}_{\mathbf{3}}$ : Mucoadhesive polymer concentration $(\mathbf{g m})$ & 0.035 & 0.07 \\
\hline $\mathbf{X}_{\mathbf{4}}:$ the type of plasticizer $(\mathbf{0 . 1 5} \mathbf{g m})$ & Glycerin & PEG 400 \\
\hline
\end{tabular}

\section{B. Preparation of Ropinirole Hydrochloride Buccal films Using Chitosan}

Based on preliminary studies, buccal films of $\mathrm{RHCl}$ were prepared by the solvent casting method (Koland et al., 2011, Raghavendra and Suryakar, 2011) using chitosan different concentrations ( $1 \& 1.5 \%$ w/v). PVP K25 \& K30 were incorporated into the films to improve the RHCL release properties from formulation. Glycerin and PEG 400 were used as film plasticizers.

Known weight of chitosan was dissolved in $20 \mathrm{ml}$ of $1 \% \mathrm{v} / \mathrm{v}$ acetic acid as solvent under stirring to produce 1 or $1.5 \% \mathrm{w} / \mathrm{v}$ solutions. The formed chitosan solution was filtered with nylon gauge and the PVP (K25 or K30), the plasticizers (glycerin or P.E.G.400) were added with continuous agitation till complete dissolution. Then, calculated conc. of $\mathrm{RHCl}\left(1.71 \mathrm{mg} / \mathrm{cm}^{2}\right)$ was dissolved in the formed solution under constant stirring. Finally, the formed solution was kept overnight for deaeration and swelling of the chitosan. The films were then poured into black plastic moulds (inner diameter $4.5 \mathrm{~cm}$ ) and dried at room temperature in the dark. The prepared $\mathrm{RHCl}$ films were carefully removed, checked for air bubbles. Films were packed in cellophane paper and stored in air tight amber glass containers to protect from light and to maintain their integrity and elasticity. The compositions of the various prepared $\mathrm{RHCl}$ films were shown in table (2). 
Table (2): The composition of the various prepared RHCL Buccal Mucoadhesive Chitosan Films according to $2^{4}$ full factorial design.

\begin{tabular}{|c|c|c|c|c|}
\hline Formulae & $\begin{array}{c}\mathbf{X}_{\mathbf{1}} \\
\text { Conc. Of } \\
\text { Chitosan }\end{array}$ & $\begin{array}{c}\mathbf{X}_{\mathbf{2}} \\
\text { Type of } \\
\text { mucoadhesive } \\
\text { polymers }\end{array}$ & $\begin{array}{c}\mathbf{X}_{3} \\
\text { Conc. of } \\
\text { mucoadhesive } \\
\text { polymers }\end{array}$ & Plastizier Type \\
\hline F1 & $1 \%$ & PVPK 25 & 0.035 & glycerin \\
\hline F2 & $1 \%$ & PVPK 25 & 0.035 & PEG400 \\
\hline F3 & $1 \%$ & PVPK 25 & 0.07 & glycerin \\
\hline F4 & $1 \%$ & PVPK 25 & 0.07 & PEG400 \\
\hline F5 & $1 \%$ & PVPK30 & 0.035 & glycerin \\
\hline F6 & $1 \%$ & PVPK30 & 0.035 & PEG400 \\
\hline F7 & $1 \%$ & PVPK30 & 0.07 & glycerin \\
\hline F8 & $1 \%$ & PVPK30 & 0.07 & PEG400 \\
\hline F9 & $1.5 \%$ & PVPK 25 & 0.035 & glycerin \\
\hline F10 & $1.5 \%$ & PVPK 25 & 0.035 & PEG400 \\
\hline F11 & $1.5 \%$ & PVPK 25 & 0.07 & glycerin \\
\hline F12 & $1.5 \%$ & PVPK 25 & 0.07 & PEG400 \\
\hline F13 & $1.5 \%$ & PVPK30 & 0.035 & glycerin \\
\hline F14 & $1.5 \%$ & PVPK30 & 0.035 & PEG400 \\
\hline F15 & $1.5 \%$ & PVPK30 & 0.07 & glycerin \\
\hline F16 & $1.5 \%$ & PVPK30 & 0.07 & PEG400 \\
\hline
\end{tabular}

* Each film ( diameter $4.5 \mathrm{~cm}$ - cross sectional area $15.91 \mathrm{~cm}^{2}$ ) contains $1.71 \mathrm{mg} / \mathrm{cm}^{2}$ of Ropinirole Hydrochloride ( equivalent to $1.5 \mathrm{mg}$ Ropinirole base)

IV. In-vitro Characterization of the Prepared Ropinirole Hydrochloride Buccal Mucoadhesive Chitosan Films:

\section{Physical Appearance, Weight and Thickness Uniformity}

Prepared $\mathrm{RHCl}$ buccal films were examined visually to determine their colour and transparency.

Weight uniformity was tested in three different randomly selected prepared circular films $(4.5 \mathrm{~cm}$ in diameter) for each formula using analytical balance (Sartorius, Germany) and average was taken. Thickness of films was measured by using standard screw gauge at three different spots of the prepared films and the average thickness was calculated (Giradkar et al., 2010).

\section{Folding Endurance}

The number of times the film could be mechanically folded at the same place without breaking gives the value of the folding endurance (Nafee et al., 2003). Folding a small strip $(2 \times 1 \mathrm{~cm})$ of the film at least up to 300 times was considered suitable for revealing satisfactory film properties. This procedure was carried out in triplicate and the average values were recorded.

\section{Drug Content Uniformity}

Drug content uniformity was determined by dissolving $\mathrm{RHCl}$ film $(4.5 \mathrm{~cm}$ in diameter) in $15 \mathrm{ml}$ of $1 \% \mathrm{v} / \mathrm{v}$ acetic acid for six hours, with occasional shaking using a Water Bath Shaker (BS-11, USA) and diluted to $100 \mathrm{ml}$ with distilled water. After 
filtration through a $0.45 \mu \mathrm{m}$ whatman filter paper, $1 \mathrm{ml}$ of the filtrate was diluted to 10 $\mathrm{ml}$ with simulated salivary fluid buffer of $\mathrm{pH} 6.75$.

Sample was analyzed using a validated HPLC method of analysis at $249 \mathrm{~nm}$ using HPLC apparatus (1260 Infinity Series, Agilent, USA). The standard curve for RHCL was established in simulated salivary fluid buffer ( $\mathrm{pH}$ 6.75). This procedure was carried out in triplicate for the films of all formulations and the average values were recorded. (composition of 1 litre simulated salivary fluid buffer: Disodium hydrogen phosphate $2.382 \mathrm{gm}$, Sodium Chloride $8 \mathrm{gm}$, Potassium dihydrogen Phosphate $0.19 \mathrm{gm}$ ) (Kshirasagar et al., 2012).

\section{Surface pH Measurement}

To measure the surface $\mathrm{pH}$ of the $\mathrm{RHCl}$ buccal films, a combined glass electrode of $\mathrm{pH}$ meter ( Model 3510, Jenway, USA) was used according to Patel (Patel et al., 2007). Films were allowed to swell in $2 \mathrm{~mL}$ of distilled water $(\mathrm{pH} 6.5 \pm 0.05)$ for 2 hours at room temperature. The $\mathrm{pH}$ was then measured by bringing the electrode into contact with the surface of the films after equilibration for 1 minute. Measurements were performed in triplicate, and average values were reported.

\section{Radial Swelling Measurement}

It was determined using the diameter method. After determination of the film diameter $(4.5 \mathrm{~cm}$ in diameter), the film was allowed to swell on the surface of an agar plate kept in an oven (Unitemp, USA) maintained at $37{ }^{\circ} \mathrm{C}$. The agar plates were prepared by dissolving $2 \%(\mathrm{w} / \mathrm{v})$ agar in warmed simulated salivary fluid Buffer $\mathrm{pH}$ 6.75 under stirring and then pouring the solution into petri dishes to gel at room temperature. Measurements of the diameter of the swollen films were done after one hour intervals for 6 hours. Radial swelling was calculated from the following equation:

$$
\text { SD }(\%)=[(D t-\text { Do }) / \text { Do }] \times 100
$$

where SD (\%) is the percent swelling, Dt is the diameter of the film after time $\mathbf{t}$, and Do is the original diameter of the film at time zero (Kshirasagar et al., 2012). This procedure was carried out in triplicate and the average values were recorded.

\section{Swelling Index Measurement}

Swelling Index determination of the RHCl films were conducted in the simulated salivary fluid buffer of $\mathrm{pH}$ 6.75. The film was weighed and placed in a preweighed stainless steel wire sieve of approximately $800 \mu \mathrm{m}$ mesh. The mesh containing the film sample was then submerged in a petri dish in $25 \mathrm{~mL}$ of the buffer and maintained at $37{ }^{\circ} \mathrm{C}$ in an oven (Unitemp, USA). At regular one hour intervals, the stainless steel mesh was removed from the dish and the excess moisture was removed by carefully wiping it off with absorbent tissue, after which it was reweighed. Increase in weight of the film was determined at each time interval until a constant weight was observed. The degree of swelling was calculated using the formula:

$$
\text { S.I. }=\left(\mathbf{W}_{\mathbf{t}}-\mathbf{W}_{\mathbf{0}}\right) / \mathbf{W}_{\mathbf{0}}
$$

where S.I. is the Swelling Index, $\mathrm{W}_{\mathrm{t}}$ is the weight of film at time " $t$ " (weight of swollen film) and $\mathrm{W}_{0}$ is the weight of the film at time "0" (weight of dry film). This procedure was carried out in triplicate and the average values were recorded (Edsman and Hagerstrom, 2005). 


\section{Ex-vivo Mucoadhesion Evaluation}

\section{A. Ex-vivo Mucoadhesive Strength Measurement}

The force required to detach the bioadhesive film from the mucosal surface was measured, using TX-TA Texture Analyzer (Microstablesystem, UK) to evaluate the bioadhesive performance of the prepared RHCl buccal films. Fresh Chicken cheek pouch was used as the model surface for bioadhesion testing. After separating the chicken mucosal membrane, it was wetted with simulated salivary fluid Buffer $\mathrm{pH} 6.75$ at $37^{\circ} \mathrm{C}$ and then mounted immediately onto a base of texture analyzer. The peak detachment force was measured at the following parameters; probe speed $(30 \mathrm{~mm} / \mathrm{min})$, trigger point $(5 \mathrm{gm})$, target value $(1.5 \mathrm{~cm})$ and hold time $(100 \mathrm{sec})$. Then, it was used to evaluate the mucoadhesion strength of the RHCL films using the following equation

\section{Force of adhesion $\mathrm{N}=$ Mucoadhesive strength $\mathrm{gm} / 1000 \times 9.8$}

Each measurement was repeated three times (Luana Periolia, 2004)

\section{B. Ex-vivo Mucoadhesion Time Measurement (Residence Time)}

The time taken for the applied buccal film on fresh mucosa to detach was recorded as the residence time of the mucoadhesive buccal formulation; i.e. the ex-vivo mucoadhesion time. Modified USP disintegration apparatus (Sotax, USA) was used to determine mucoadhesion time (Goud et al., 2011).

Fresh sheep buccal mucosal membrane was used and cut to an appropriate size of a $(3 \times 3 \mathrm{~cm})$ square film and fixed on the glass slides with cyanoacrylate glue. The film was first wetted with $0.5 \mathrm{~mL}$ of simulated salivary fluid Buffer $\mathrm{pH} 6.75$ and attached to the buccal tissue by pressing it lightly with a finger tip for 20 seconds. Then after ten minutes of contact time, the slides were hanged vertically to the apparatus using $800 \mathrm{~mL}$ of the aforementioned buffer maintained at $37 \pm 0.5^{\circ} \mathrm{C}$. The films were completely immersed in the buffer solution at the lowest point and was out at the highest point during the up and down movement of the disintegration apparatus operation. The experiments were performed in triplicate and the average was calculated.

\section{In-vitro Drug Release Study}

USP type V dissolution Tester (paddle over disk, Hanson SR8 plus, Hanson Research Lab., USA) was used to study the RHCL release from the buccal films. RHCl films were allowed to diffuse the drug from one surface only by backing from one side using ethyl cellulose due to its water impermeable nature (Guo and Cooklock, 1996). Then, films were glued with cyanoacrylate adhesive on $5 \mathrm{~cm}$ glass watch and covered with an inert PTFE (POLY TEFLON) mesh with hole size $(0.145 \times 0.360 \mathrm{IN})$. This is placed at the bottom of the vessel, with the mesh facing upwards, under the rotating paddle (Kumar et al., 2014).

The release was performed using $500 \mathrm{ml}$ of simulated salivary buffer of $\mathrm{pH} 6.75$ as the dissolution medium. The temperature of the dissolution medium was maintained at $37 \pm 0.5^{\circ} \mathrm{C}$ and the release study was performed with a rotation speed of $50 \mathrm{rpm}$ for 6 hours.

Samples of $5 \mathrm{ml}$ were withdrawn at the predetermined sampling times $(15,30$, $45,60,90,120,180,240,300 \& 360$ minutes) and replaced with the fresh medium. The 
samples were filtered and drug concentrations were determined using the validated HPLC method of analysis at $249 \mathrm{~nm}$.

The release from different films was conducted in triplicate and average values were recorded.

The release kinetics such as zero order, first order, Higuchi and Hixson- Crowell were determined.

\section{Stability Study for the Prepared Ropinirole Hydrochloride Buccal Mucoadhesive Chitosan Films:}

\section{A. Stability Study in Human Saliva}

The stability study of the RHCL buccal films was done using natural human saliva (Desai and Kumar, 2004). The prepared films were placed in petri dishes, each containing $5 \mathrm{~mL}$ of human saliva (collected from humans of ages 18 up to 50 years). Then, films were put in a temperature-controlled oven (Unitemp, USA) at $37^{\circ} \mathrm{C}$ for 6 hours examined at regular time intervals $(0,1,2,3$, and 6 hours) for changes in color and shape, film collapse and drug concentration. This procedure was performed in triplicate, and average values were reported.

\section{B. Long Term Stability Study}

The stability study was conducted for the selected optimized prepared film formulae for one year according to the ICH guidelines to test the effect of storage on its' mechanical properties and $\mathrm{RHCl}$ release rate from the films. These films were wrapped in cellophane paper and protected from light in an air tight amber glass container. Films were subjected to stress conditions by storing it for one year at $30^{\circ} \mathrm{C} \pm 2{ }^{\circ} \mathrm{C}$ with $65 \% \pm$ $5 \%$ relative humidity using saturated solution of sodium chloride.

Samples were examined for any physical change, mucoadhesion properties (exvivo mucoadhesive strength) as well as their release rate every 3 months (Chinchole $\boldsymbol{e t}$ al., 2014).

\section{RESULTS AND DISUSSION}

Results of the preliminary study showed that, the RHCl buccal chitosan films prepared using the mucoadhesive polymers sodium carboxymethyl cellulose, hydroxypropyl methyl cellulose in concentrations of $0.5,1,1.5$ and $2 \%$ gave hardly pealed, opaque films with undissolved precipitate. So, these polymers were rejected.

Also, results showed that the $\mathrm{RHCl}$ buccal chitosan films with better physical appearance and characteristics and good peeling were prepared using $1 \%$ acetic acid as the casting solvent, with the mucoadhesive polymers PVP (K25 \& K30).

Results showed that using glycerol \& PEG 400 at concentration of $0.15 \mathrm{gm}$ as plasticizers gave high flexablility to the prepared films and were better than propylene glycol which gave films with bad elasticity and rejected.

So, sodium carboxymethyl cellulose, hydroxypropyl methyl cellulose and propylene glycol were excluded and were not involved in the factorial design. 


\section{Physicochemical Compatibility Study}

\section{A. Differential Scanning Calorimetric (DSC) Study}

Fig. (1) shows the DSC thermograms of Ropinirole HCL, chitosan, PVPK25 \& PVPK30. The DSC thermogram of the RHCl exhibits a sharp endothermic peak at $245.94^{\circ} \mathrm{C}$ corresponding to its melting transition temperature (Panchal et al., 2012). The DSC thermograms show small peaks (due to the amorphous nature of polymers) at $112.39^{\circ} \mathrm{C}, 118.22{ }^{\circ} \mathrm{C}, 114.89^{\circ} \mathrm{C}$ for chitosan, PVPK25 \& PVPK30 respectively which properly corresponds to its melting points.

The DSC thermograms of drug: polymer physical mixtures (ratio 1:1 w/w) with chitosan, PVPK25, PVPK30 shows no change in drug melting peaks in the thermogram of the physical mixture where the polymer increases the melting point of Ropinirole hydrochloride and broadens its melting point endotherm from $245.94^{\circ} \mathrm{C}$ to $254.33^{\circ} \mathrm{C}$, $256.96^{\circ} \mathrm{C}, 253.56^{\circ} \mathrm{C}$ or $2557.52^{\circ} \mathrm{C}$ with chitosan, PVPK25 and PVPK30 respectively. The endothermic peaks of the polymers disappeared for chitosan, shifted and slightly broadened from $118.22^{\circ} \mathrm{C}$ to $97.54^{\circ} \mathrm{C}$ and from $114.98^{\circ} \mathrm{C}$ to $109.62^{\circ} \mathrm{C}$ for PVPK25 \& PVPK30 respectively. The slight change in melting temperature of drug may be attributed to amorphous polymers.

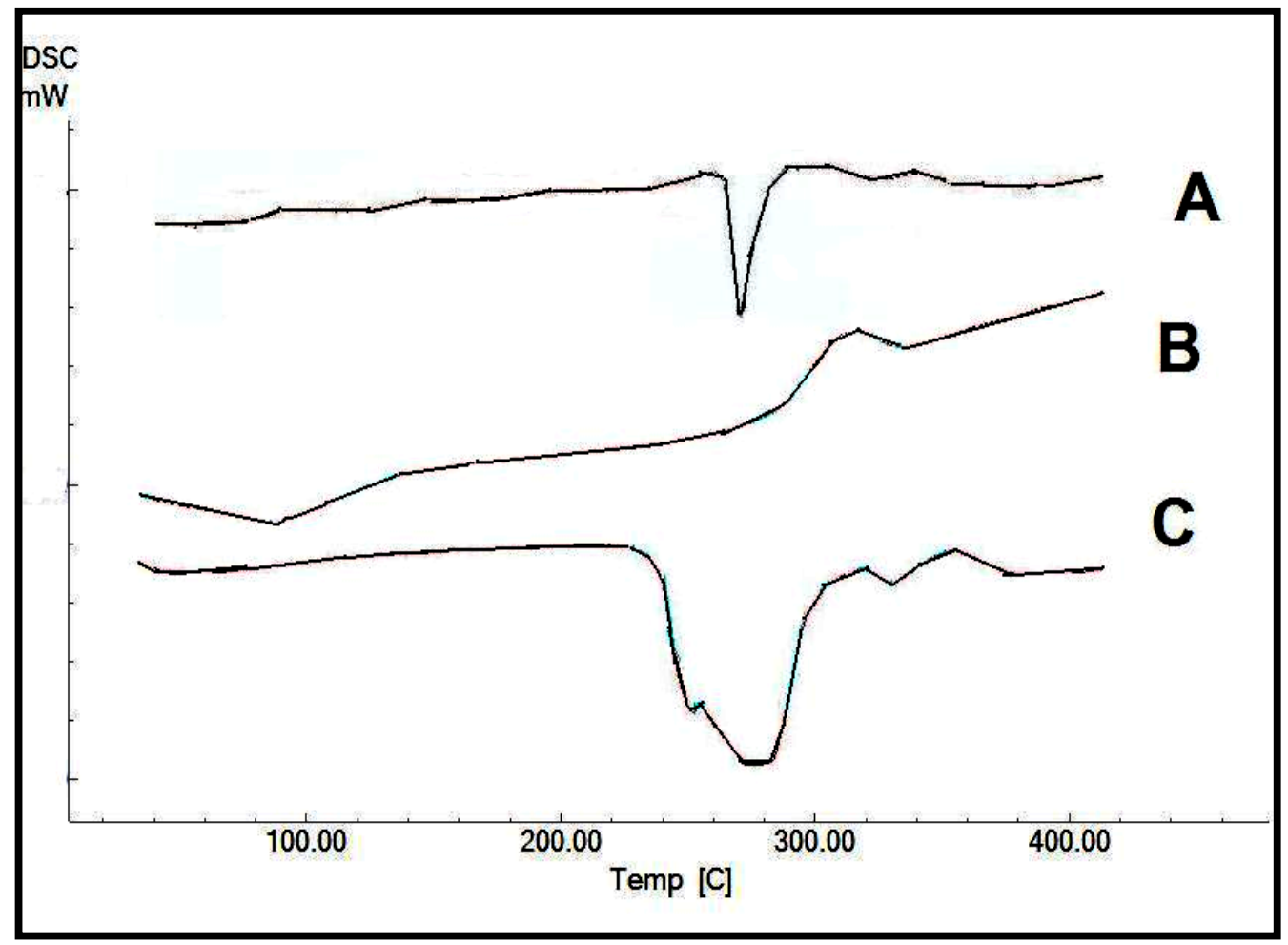

DSC Thermograms of : (A) RHCl (B) chitosan (C) RHCl: chitosan (1 : 1) physical mixture. 


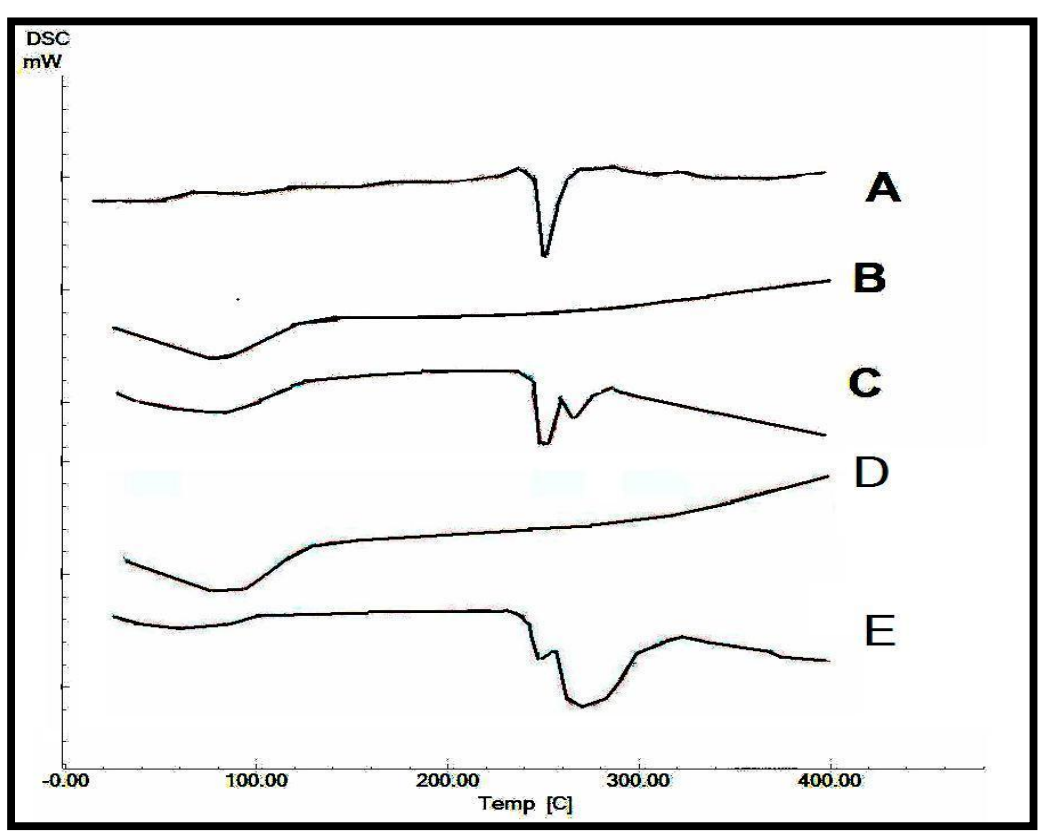

DSC Thermograms of : (A) RHCl (B) PVPK25 (C) RHCl: PVPK25 (1 : 1) physical mixture, (D) PVPK30 (E) RHCl: PVPK30 (1 : 1) physical mixture.

Fig. (1): DSC Thermograms of RHCl, used mucoadhesive polymers \& RHCl: polymer physical mixtures

\section{B. Fourier Transform Infrared (FTIR) Study}

IR spectroscopy can investigate the interaction between drug and the used polymers. The principal IR spectrum assigned to pure drug RHCL in fig. (2) displays peaks at $1392.35 \mathrm{~cm}^{-1}\left(-\mathrm{CH}_{3}\right.$ bending), $1457.25 \mathrm{~cm}^{-1}$ (C=C stretching), $1703.17 \mathrm{~cm}^{-1}$ ( $\mathrm{C}=\mathrm{O}$ stretching) and $3144.02 \mathrm{~cm}^{-1}$ (N-H stretching) (Panchal et al., 2012, Chandra et al., 2015).

The characteristic peaks of chitosan were seen at 1650 and $1590 \mathrm{~cm}^{-1}$ corresponding to amide and amino groups. In the infrared spectrum, powder chitosan exhibited a broad peak at $3443.28 \mathrm{~cm}^{-1}$ which is assigned to the $\mathrm{N}-\mathrm{H}$ and hydrogen bonded $\mathrm{O}-\mathrm{H}$ stretch vibrational frequencies, while a sharp (shoulder) peak at $3610 \mathrm{~cm}^{-1}$ is that of free $\mathrm{O}-\mathrm{H}$ bond stretch of glucopyranose units. Further, in the $\mathrm{C}-\mathrm{H}$ stretch region of FTIR spectrum, the higher intensity peak at $2922.59 \mathrm{~cm}^{-1}$ is assigned to the asymmetric and the lower intensity peak at $2923 \mathrm{~cm}^{-1}$ is assigned to symmetric modes of $\mathrm{CH}_{2}$. In addition, the characteristic band due to $\mathrm{CH}_{2}$ scissoring, which usually occurs at $1378.85 \mathrm{~cm}^{-1}$ was also present in the sample (Kshirasagar, 2012, Tejada et al., 2017). Since the grade of chitosan used is $85 \%$ deacetylated, an amide bond was present in the spectra and the $\mathrm{C}=\mathrm{O}$ stretch of amide bond was observed at $1642.09 \mathrm{~cm}^{-1}$. Peaks at 1550 and $1599 \mathrm{~cm}^{-1}$ were assigned to strong $\mathrm{N}-\mathrm{H}$ bending vibrations of secondary amide, which usually occur in the range of 1640 to $1550 \mathrm{~cm}^{-1}$ as strong band FTIR spectra as seen in fig. (2) for the used polymers and drug : polymer physical mixture (ratio 1:1). FTIR spectra revealed that there were no considerable changes in the IR 
peaks of $\mathrm{RHCl}$ when mixed with excipients, indicating there was no interaction between $\mathrm{RHCl}$ and used polymers and that $\mathrm{RHCl}$ had maintained its identity without losing its characteristic properties.

From the results obtained in the present study, it can be concluded that the FTIR and DSC studies showed that there is no drug-polymer incompatibility.

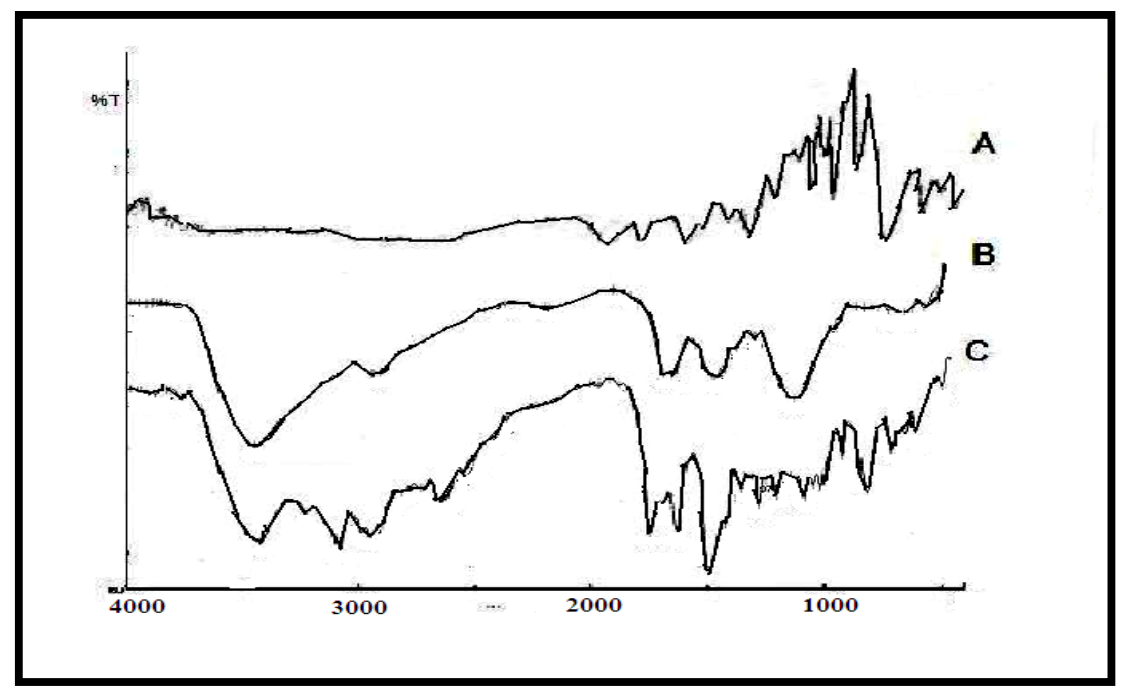

Infrared Spectra of : (A) RHCl (B) chitosan (C) RHCl: chitosan (1 : 1) physical mixture

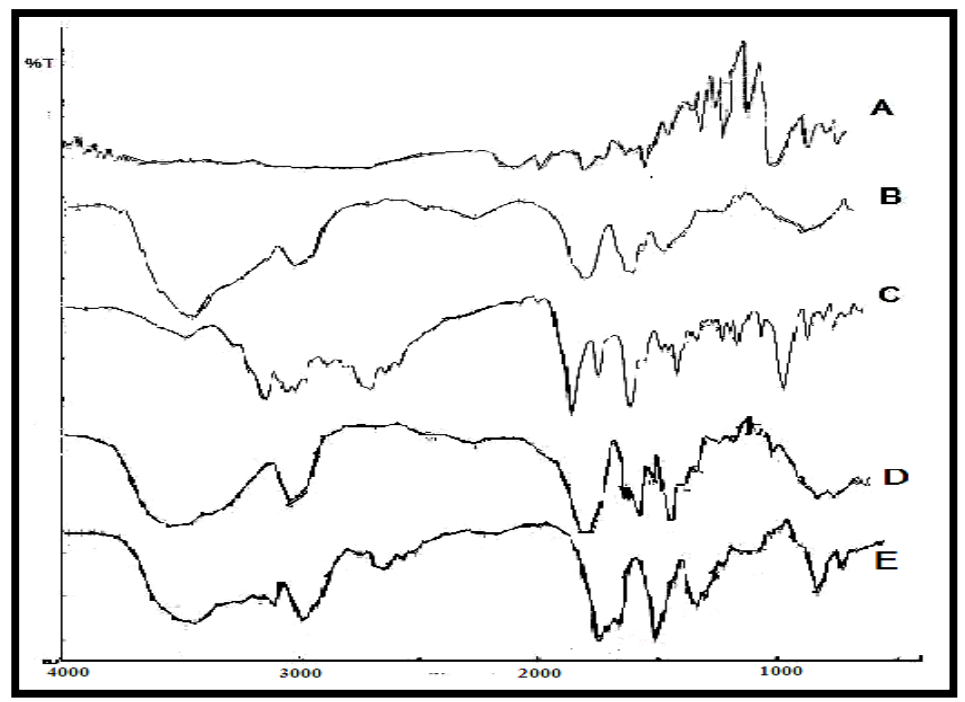

Infrared Spectra of : (A) RHCl, (B) PVPK25, (C) RHCl: PVPK25 (1 : 1) physical mixture, (D) PVPK30, (E) RHCl: PVPK30 (1 : 1) physical mixture.

Fig. (2): Infrared Spectra of RHCl, used muoadhesive polymers \& RHCl: polymer physical mixtures.

In-vitro characterization of the Prepared Ropinirole Hydrochloride Buccal Mucoadhesive Chitosan Films

RHCl buccal films using chitosan were prepared by $2^{4}$ full factorial design to obtain good physical properties. The formulated RHCL buccal mucoadhesive chitosan 
films were satisfactory in terms of physical parameters. The addition of plasticizer imparts flexibility to films with increased thickness, easily removed without damage to film configuration (Boateng $\boldsymbol{e t}$ al., 2009). Thus glycerol and PEG 400 (0.15gm) were used in all formulated films resulting in optimal plasticized films. The composition of prepared films were represented in Table (2).

RHCl Films were yellow, translucent, smooth, flexible with no visible cracks, with uniform weight and thickness.

The weight of the RHCl buccal films was in the range of $109 \pm 1.52$ $225 \pm 1.76 \mathrm{mg}$. The thickness of all films was uniform within each formulation and in

the range of $0.2 \pm 0.05-0.60 \pm 0.05 \mathrm{~mm}$. Films with increased polymer content showed a slight increase in thickness. Weights \& thickness of the films increased with increasing the chitosan \& PVP K25 or PVPK30 concentration.

Table (3): Physicochemical Parameters of RHCI Buccal Mucoadhesive Chitosan Films

$*$ N.B.: The values were represented as average \pm S.D.

\begin{tabular}{|c|c|c|c|c|}
\hline Formula & $\begin{array}{c}\text { Weight* } \\
(\mathbf{m g})\end{array}$ & $\begin{array}{c}\text { Thickness* } \\
(\mathbf{m m})\end{array}$ & $\begin{array}{c}\text { Surface } \\
\mathbf{p H}^{*}\end{array}$ & $\begin{array}{c}\text { Drug Content* } \\
(\boldsymbol{\%})\end{array}$ \\
\hline F1 & $109 \pm 1.52$ & $0.20 \pm 0.05$ & $6.45 \pm 0.10$ & $92.5 \pm 2.10$ \\
\hline F2 & $149 \pm 1.15$ & $0.25 \pm 0.05$ & $6.71 \pm 0.12$ & $93.5 \pm 1.52$ \\
\hline F3 & $126 \pm 1.53$ & $0.30 \pm 0.05$ & $6.80 \pm 0.05$ & $95.6 \pm 1.35$ \\
\hline F4 & $147 \pm 1.81$ & $0.35 \pm 0.05$ & $6.75 \pm 0.07$ & $92.2 \pm 1.41$ \\
\hline F5 & $123 \pm 1.72$ & $0.25 \pm 0.05$ & $6.57 \pm 0.14$ & $93.4 \pm 1.26$ \\
\hline F6 & $185 \pm 1.34$ & $0.25 \pm 0.05$ & $6.69 \pm 0.13$ & $94.1 \pm 1.84$ \\
\hline F7 & $128 \pm 1.42$ & $0.30 \pm 0.05$ & $6.70 \pm 0.10$ & $96.5 \pm 0.95$ \\
\hline F8 & $185 \pm 1.57$ & $0.35 \pm 0.05$ & $6.75 \pm 0.09$ & $96.3 \pm 1.94$ \\
\hline F9 & $169 \pm 1.52$ & $0.40 \pm 0.05$ & $6.81 \pm 0.15$ & $93.1 \pm 2.31$ \\
\hline F10 & $173 \pm 1.36$ & $0.45 \pm 0.05$ & $6.80 \pm 0.18$ & $94.5 \pm 1.39$ \\
\hline F11 & $194 \pm 1.47$ & $0.50 \pm 0.05$ & $6.79 \pm 0.07$ & $95.6 \pm 1.82$ \\
\hline F12 & $200 \pm 1.12$ & $0.55 \pm 0.05$ & $6.82 \pm 0.05$ & $96.8 \pm 1.42$ \\
\hline F13 & $178 \pm 1.48$ & $0.50 \pm 0.05$ & $6.87 \pm 0.08$ & $93.5 \pm 1.78$ \\
\hline F14 & $174 \pm 1.56$ & $0.55 \pm 0.05$ & $6.78 \pm 0.05$ & $95.7 \pm 2.43$ \\
\hline F15 & $194 \pm 1.22$ & $0.55 \pm 0.05$ & $6.66 \pm 0.12$ & $91.3 \pm 1.56$ \\
\hline F16 & $225 \pm 1.76$ & $0.60 \pm 0.05$ & $6.75 \pm 0.07$ & $91.5 \pm 2.18$ \\
\hline
\end{tabular}

All films formulae showed good folding endurance $(>300)$, indicating good flexibility and elasticity with high mechanical strength of the films that is necessary for handling. It was also observed that when polymer concentration increases, folding endurance of film increases.

The observed good physicochemical parameters of the prepared films, perhaps might be due to the film-forming property of chitosan. Films containing a higher concentration of PVP showed better physical appearance due to the PVP's film-forming property.

The $\mathrm{RHCl}$ content in the buccal films was uniform ranging from 91.3 to $96.8 \%$ ensuring that $\mathrm{RHCl}$ was uniformly dispersed throughout the films. Table (3) shows the 
measured physicochemical parameters of $\mathrm{RHCl}$ buccal mucoadhesive chitosan films.

Surface $\mathrm{pH}$ measurement could predict any possibility of any side effects in vivo where changing of buccal mucosal $\mathrm{pH}$ from neutral $\mathrm{pH}$ to either acidic or alkaline $\mathrm{pH}$ might cause irritation. $\mathrm{RHCl}$ buccal films surface $\mathrm{pH}$ was in range of $6.45 \pm 0.10$ to $6.87 \pm 0.08$, close to the natural $\mathrm{pH}$ and with no observed significant difference between different formulae. This ensured its safety on mucosal application without expected local irritation.

\section{Radial Swelling Measurement}

The swelling behavior of any bioadhesive polymer affects significantly its mucoadhesion and consequently the drug release from the matrix. Bioadhesion increases by increasing the degree of hydration until a point where overhydration leads to an abrupt drop in adhesive strength, due to disentanglement at the polymer tissue interface (Eouani et al.,2001). Radial swelling measurement was a good assessment of the swelling behavior of the prepared $\mathrm{RHCl}$ films as shown in table (4). Formula F12 showed the highest radial swelling followed by F11, F4, F3, F10, F9, F2 then F1. The swelling behavior of films was found to be directly proportional to the concentration of the mucoadhesive polymers chitosan and PVP concentrations.

\section{Swelling Index Measurement}

All films showed considerable swelling without any noticeable changes in its shape. The swelling behavior of films was found to be directly proportional to the concentration of chitosan where the percent swelling index increased as the concentration of chitosan increased.

Also, the swelling behavior of films was found to be directly proportional to PVP (K25\& K30) concentrations and the time. This could be due to increasing surface wetting and, consequently, water penetration within the film matrix. Addition of PVPK25, PVPK30 polymers to RHCl chitosan films caused an increase of swelling behavior in the following descending order:

PVPK25 (0.07gm) with PEG400 than glycerin (F12, F11, F4, F3) > PVPK25 $(0.035 \mathrm{gm})$ with PEG400 than glycerin (F10, F9, F2, F1) > PVPK30 with PEG400 $(1.5 \%$ w/v chitosan $)(\mathrm{F} 16, \mathrm{~F} 14)>$ PVPK30 with glycerin $(1.5 \% \mathrm{w} / \mathrm{v}$ chitosan) $(\mathrm{F} 15, \mathrm{~F} 13)$ . The swelling index varied from $0.19-0.86$ as shown in Table (4). Thus, it can be concluded that the concentration of PVP had a good effect on the swelling index of the chitosan matrix.

\section{Ex-vivo Mucoadhesion Evaluation}

\section{A. Ex-vivo mucoadhesive strength measurement}

The ex-vivo mucoadhesive strength of all formulae measured after ten minutes of initial contact time with the buccal mucosa varied from $10.23 \pm 0.89$ to $24.33 \pm 0.39$ as shown in table (4).

The mucoadhesive strength was increased linearly with increasing concentration of chitosan, where formulae F9-F16 have higher values than formulae F1 to F8. It was stated from literature that upon contact with natural mucosa and being wetted, amine groups of the chitosan polymer become protonated, with a resultant positively charged soluble polysaccharide $\left(\mathrm{RNH}^{+}\right)$. It has been proposed that positive charges on the 
surface of chitosan could give rise to a strong electrostatic interaction with mucus or negatively charged mucosal surface (He et al., 1999)

Also, it was observed that the mucoadhesive strength decreased linearly with increasing concentration of PVP.

The results also indicated that the effect of concentration of chitosan was more significant than the effect of concentration of PVP. Results showed that the detachment force increased by increasing the concentration of the polymer, since the increase in the concentration led to an increase in the functional groups responsible for hydrogen bond formation.

\section{B. Ex-vivo mucoadhesion time mearurement}

The ex-vivo mucoadhesion residence time of all formulations was within a range of 45 to $120 \mathrm{~min}$. and all the results are shown in table (4).

The ability of polymer to swell quickly promotes rapid interaction with the mucin, due to the large adhesive surface, leading to good adhesion.

Increasing chitosan concentration increased residence time than increasing PVP concentrations.

\begin{tabular}{|c|c|c|c|c|}
\hline Formula & $\begin{array}{c}\text { Radial } \\
\text { Swelling (\%) }\end{array}$ & $\begin{array}{c}\text { Swelling } \\
\text { Index }\end{array}$ & $\begin{array}{c}\text { Ex-vivo } \\
\text { Mucoadhesion } \\
\text { Time (min) }\end{array}$ & $\begin{array}{c}\text { Ex-vivo } \\
\text { Mucoadhesive } \\
\text { Strength (N) } \pm \text { SD }\end{array}$ \\
\hline F1 & 26.83 & 0.40 & 54 & $12.85 \pm 0.51$ \\
\hline F2 & 28.89 & 0.43 & 60 & $13.97 \pm 0.38$ \\
\hline F3 & 48.78 & 0.73 & 70 & $14.98 \pm 0.69$ \\
\hline F4 & 51.11 & 0.77 & 80 & $16.18 \pm 0.45$ \\
\hline F5 & 12.50 & 0.19 & 45 & $10.23 \pm 0.89$ \\
\hline F6 & 15.56 & 0.23 & 48 & $11.98 \pm 0.68$ \\
\hline F7 & 15.56 & 0.23 & 50 & $12.24 \pm 0.98$ \\
\hline F8 & 19.51 & 0.29 & 52 & $12.63 \pm 0.75$ \\
\hline F9 & 30.95 & 0.46 & 109 & $20.42 \pm 0.58$ \\
\hline F10 & 40.00 & 0.60 & 113 & $22.57 \pm 0.40$ \\
\hline F11 & 54.50 & 0.82 & 118 & $24.25 \pm 0.77$ \\
\hline F12 & 57.50 & 0.86 & 120 & $24.33 \pm 0.39$ \\
\hline F13 & 20.00 & 0.30 & 86 & $16.67 \pm 0.54$ \\
\hline F14 & 21.95 & 0.33 & 90 & $17.71 \pm 0.69$ \\
\hline F15 & 22.22 & 0.33 & 98 & $18.48 \pm 0.64$ \\
\hline F16 & 24.44 & 0.37 & 104 & $19.84 \pm 0.47$ \\
\hline
\end{tabular}

Table (4): Swelling and Ex-vivo Parameters of RHCI Buccal Mucoadhesive Chitosan Films

\section{In-vitro drug release study}

The in-vitro release profile of $\mathrm{RHCl}$ from different chitosan films is shown in Fig. (3). The release study was performed for 360 minutes and the data obtained showed that most of the prepared $\mathrm{RHCl}$ buccal films gave uniform release profile required for mucoadhesive drug delivery system. All the RHCl films formulae showed more than $50.75 \%$ to $95.25 \%$ drug release. The maximum drug release was found in 
formula F4 (95.25\% $\% 3.72 \%)$. The drug release rate was uniform from the hydrophilic polymer chitosan and appeared to increase with decreasing concentration of chitosan.

Also, the drug release rate was increased with an increasing concentration of the hydrophilic polymers PVP K25 \& K30. It was observed after conducting dissolution testing that films with higher concentrations of PVP showed considerable swelling than others. The increase in rate of drug release could be explained by the ability of the hydrophilic polymers to absorb water, thereby promoting the dissolution, and hence the release, of the highly water-soluble drug. Moreover, the hydrophilic polymers would leach out and, hence, create more pores and channels for the drug to diffuse out of the films (Bodmeier and Paeratakul, 1989).

The results also indicated that the concentration of chitosan showed more effect on drug release than the concentration of PVP. In theory, the higher the uptake of water by the polymer, the more the amount of drug diffused out from the polymer matrix (Desai \& Kumar, 2004).

The best drug release results were obtained with $\mathrm{RHCl}$ film formula $\mathrm{F} 4$ (95.25

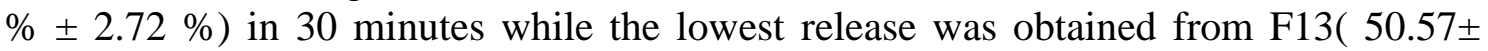
$8.72)$ in 360 minutes. The time to reach maximum release varied from 30minutes ( $\mathrm{F} 4$, F12, F2), 60mins (F3, F8, F10, F11), 90 mins ( F1, F16), 180mins (F9, F7), 240mins

(F6), 300mins ( F14) and finally 360mins ( F13).

Further to understand the order and mechanism of drug release from buccal films the data was subjected to various kinetic equations and plotted according to zero order, first order, Higuchi and Hixson- Crowell. The plots of log cumulative percentage drug release versus log time were found to be linear to the all formulations. Results are shown in table (5). The kinetic values obtained indicated that release of drug followed the diffusion controlled mechanism. 

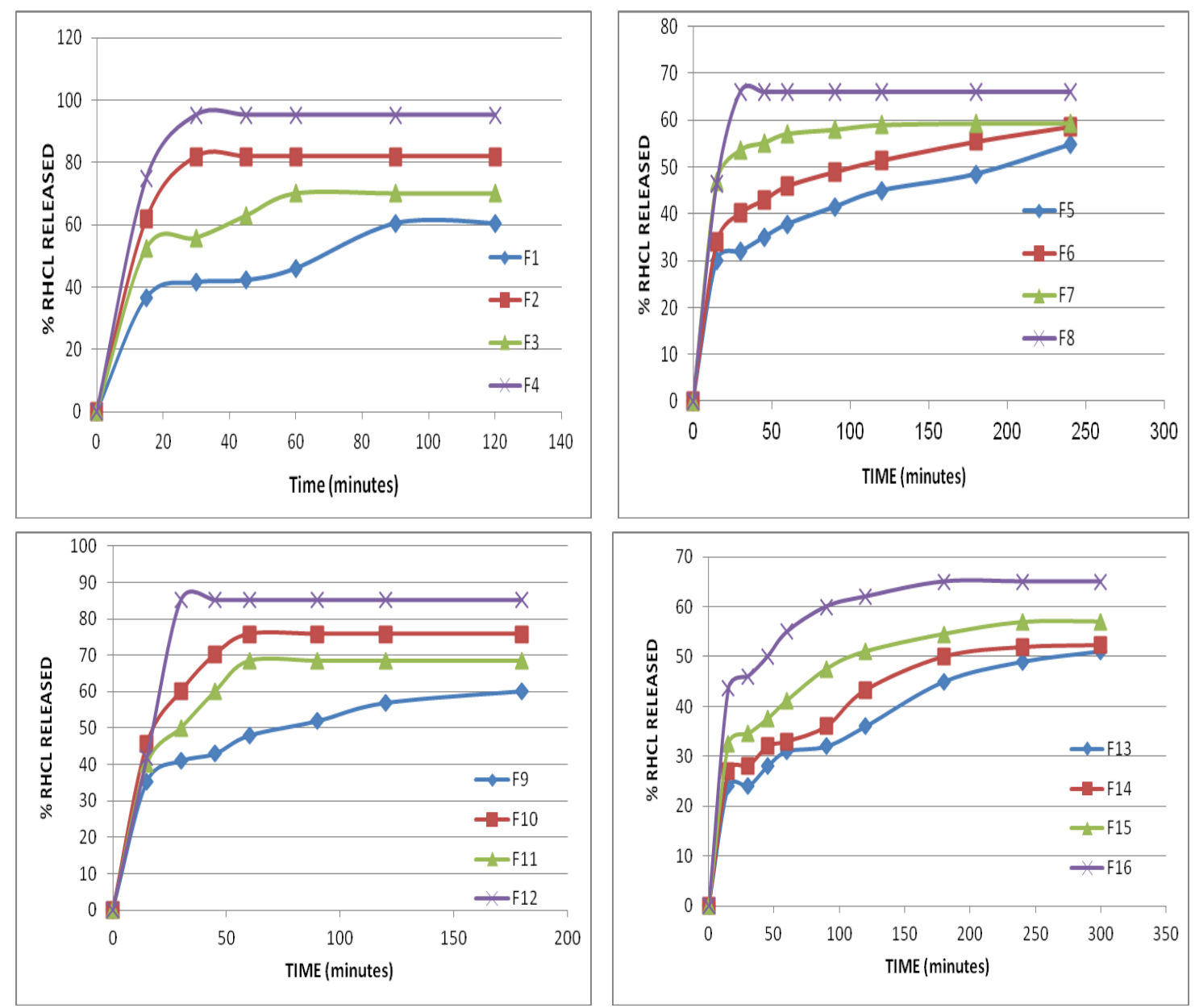

Fig. (3): In-vitro Release Profiles of RHCl Buccal Mucoadhesive Chitosan Films 
Table (5): Kinetic Parameters of RHCl Buccal Mucoadhesive Chitosan Films

N.B. : All values are average of 3 readings

\begin{tabular}{|c|c|c|c|c|}
\hline Formula & $\begin{array}{c}\text { Zero } \\
\text { Order } \\
\left(\mathbf{R}^{\mathbf{2}}\right.\end{array}$ & $\begin{array}{c}\text { First Order } \\
\left(\mathbf{R}^{\mathbf{2}}\right)\end{array}$ & $\begin{array}{c}\text { Higuchi } \\
\left.\mathbf{( R}^{\mathbf{2}}\right)\end{array}$ & $\begin{array}{c}\text { Hixon-crowel } \\
\mathbf{( R}^{\mathbf{2}} \mathbf{(}\end{array}$ \\
\hline F1 & 0.9282 & 0.953 & 0.861 & 0.9457 \\
\hline F2 & 0.9436 & 0.9242 & 0.9734 & 0.9308 \\
\hline F3 & 0.9761 & 0.9839 & 0.9378 & 0.9815 \\
\hline F4 & 0.8864 & 0.8726 & 0.9299 & 0.8772 \\
\hline F5 & 0.9699 & 0.9257 & 0.9933 & 0.936 \\
\hline F6 & 0.892 & 0.8371 & 0.9714 & 0.8555 \\
\hline F7 & 0.6146 & 0.5866 & 0.7597 & 0.5959 \\
\hline F8 & 0.871 & 0.853 & 0.9174 & 0.8589 \\
\hline F9 & 0.9184 & 0.878 & 0.9796 & 0.8926 \\
\hline F10 & 0.9624 & 0.9337 & 0.9904 & 0.9441 \\
\hline F11 & 0.9876 & 0.9985 & 0.995 & 0.9925 \\
\hline F12 & 0.8385 & 0.8141 & 0.8902 & 0.8218 \\
\hline F13 & 0.9659 & 0.9342 & 0.9761 & 0.9469 \\
\hline F14 & 0.9589 & 0.9362 & 0.9699 & 0.9452 \\
\hline F15 & 0.9024 & 0.8653 & 0.9678 & 0.8783 \\
\hline F16 & 0.8845 & 0.8571 & 0.9558 & 0.8665 \\
\hline
\end{tabular}

\section{Factorial Design Analysis and Selection of Optimized formula}

The $2^{4}$ full factorial design with statistical analysis was used for planning and analysis of experimental trials through Design-Expert ${ }^{\circledR}$ Software, version 7. Results were not shown but it is worthy to note that the predicted $R_{2}$ values for all responses were in a reasonable agreement with the adjusted $R_{2}$.

For selection of optimized formulae, it was almost impossible to achieve all the desired responses simultaneously due to the possibility of interference occurrence. The optimum condition reached in one response may possess an opposite impact on another response. Fortunately, the desirability function combines all the responses into one variable to predict the optimum levels for the studied factors (Singh et al., 2012).

So, desirability was calculated to select the optimized formula on the basis of maximum $\mathrm{RHCl}$ released (\%), maximum release rate, maximum mucoadhesive strength, and then swelling index. The calculated values of all the responses were in close accordance with the experimental results obtained (the done results and figures not shown).

Results showed that the highest desirability value was for formula F4 (chitosan $1 \%$ w/v, PVP K25 0.07gm, PEG400 1.5gm). Formula F4 showed optimized release \% with maximum rate and also good mucoadhesive strength and swelling index.

In vitro release data (represented by histogram in fig (4)) showed that formulation $\mathrm{F} 4$ showed optimized release $\%$ with maximum rate. 
Formulations F12, F11, F10 and F9 showed more mucoadhesive strength and formulations F12, F11, F4 and F3 showed highest swelling index while F4, F12, F2, F10 achieved the highest release rate.

Thus, RHCl buccal film formula F4 fitted all the desired criteria and selected as the optimized formulation.

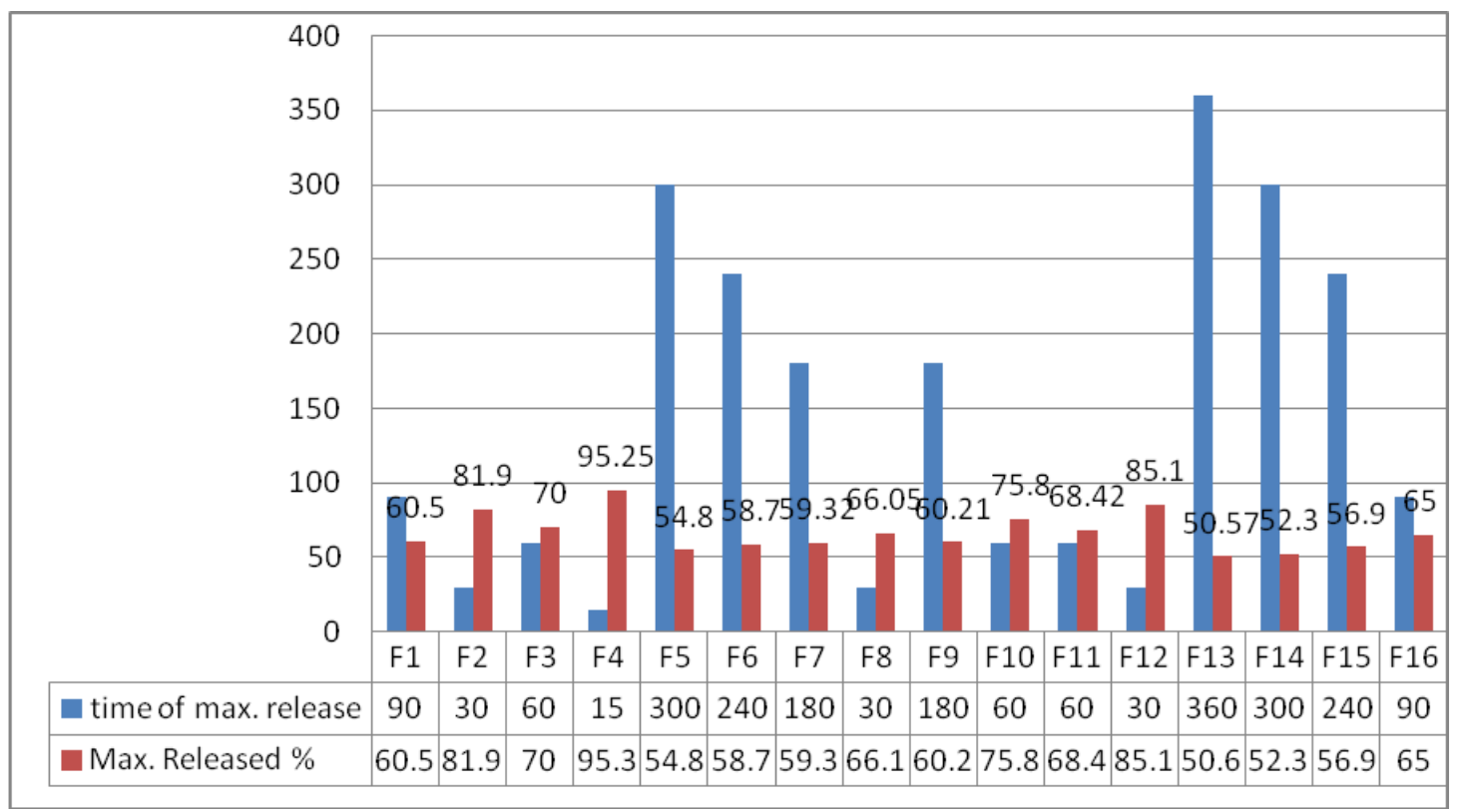

Fig. (4): Representative Histogram for the In-vitro Release Data of RHCl Buccal Mucoadhesive Chitosan Films

\section{Stability Study for the Prepared Ropinirole Hydrochloride Buccal Mucoadhesive Chitosan Films:}

\section{A. Stability Study in Human Saliva}

Conducting stability study in natural human saliva would better predict the stability of the drug in its matrix in the oral cavity in vivo. Therefore, the stability study of the optimized film F4 was evaluated in natural human saliva by its appearance (color, shape, thickness and diameter), and finally its drug content. Results are shown in table (6).

The film did not show any physical changes as well as drug concentration, indicating the satisfactory stability of the drug and the film in human saliva. In theory, if the drug is unstable in human saliva, its color would change (Choi \& Kim, 2000). Also, $\mathrm{RHCl}$ film did not collapse in the low volume of human saliva until the end of the study, confirming the sufficient strength of the film.

It was also observed that the physical properties of the optimized film, such as thickness and diameter, increased slightly due to swelling in human saliva.

\section{B. Long Term Stability Study}

Stability study of the optimized formula F4 was carried out for one year and results are shown in table (6). The films did not show any physical changes. No significant 
difference was observed in its ex-vivo mucoadhesionive strength and drug release profile. This ensured the stability of the chosen optimized film formula F4.

Table (6): Stability Data of RHCl Buccal Mucoadhesive Chitosan Films in Normal Human Saliva after six hours and after one year.

* Visual observation, ** Mean of 3 readings

\begin{tabular}{|c|c|c|c|c|c|}
\hline \multicolumn{6}{|c|}{ Stability Data in Normal Human Saliva for 6 hours } \\
\hline $\begin{array}{c}\text { Sampling } \\
\text { Time } \\
\text { (hours) }\end{array}$ & $\begin{array}{c}\text { Change in } \\
\text { Color } *\end{array}$ & $\begin{array}{c}\text { Change in } \\
\text { Shape* }\end{array}$ & $\begin{array}{c}\text { Thickness** } \\
(\mathbf{m m}) \pm \text { SD }\end{array}$ & $\begin{array}{c}\text { Diameter } \\
(\mathbf{m m}) \pm \text { SD }\end{array}$ & $\begin{array}{c}\text { RHCl } \\
\text { concentration** } \\
(\%) \pm \text { SD }\end{array}$ \\
\hline $\mathbf{0}$ & No & No & $0.35 \pm 0.05$ & $4.5 \pm 0.03$ & $92.2 \pm 1.34$ \\
\hline $\mathbf{1}$ & No & No & $0.35 \pm 0.05$ & $4.8 \pm 0.05$ & $92 \pm 2.12$ \\
\hline $\mathbf{2}$ & No & No & $0.35 \pm 0.05$ & $5.0 \pm 0.04$ & $91 \pm 1.58$ \\
\hline $\mathbf{4}$ & No & No & $0.45 \pm 0.05$ & $5.35 \pm 0.06$ & $90 \pm 1.82$ \\
\hline $\mathbf{6}$ & No & No & $0.55 \pm 0.05$ & $5.7 \pm 0.03$ & $90 \pm 1.74$ \\
\hline
\end{tabular}

Stability Data after one year (at $30^{\circ} \mathrm{C} \pm 2{ }^{\circ} \mathrm{C}$ with $65 \% \pm 5 \%$ relative humidity)

\begin{tabular}{|c|c|c|c|c|}
\hline $\begin{array}{c}\text { Sampling } \\
\text { Time } \\
\text { (hours) }\end{array}$ & $\begin{array}{c}\text { Change in } \\
\text { Color }\end{array}$ & $\begin{array}{c}\text { Change in } \\
\text { Shape* }^{*}\end{array}$ & $\begin{array}{c}\text { Ex-vivo Mucoadhesive } \\
\text { Strength** (N) } \pm \text { SD }\end{array}$ & $\begin{array}{c}\text { RHCL } \\
\text { release** } \\
\text { (\%) } \pm \text { SD }\end{array}$ \\
\hline $\mathbf{0}$ & No & No & $16.18 \pm 0.45$ & $95.25 \pm 2.45$ \\
\hline $\mathbf{3}$ & No & No & $15.54 \pm 0.54$ & $95 \pm 2.31$ \\
\hline $\mathbf{6}$ & No & No & $14.87 \pm 0.65$ & $93 \pm 1.45$ \\
\hline $\mathbf{9}$ & No & No & $14.25 \pm 0.49$ & $89 \pm 1.65$ \\
\hline $\mathbf{1 2}$ & No & No & $12.47 \pm 0.74$ & $90 \pm 1.45$ \\
\hline
\end{tabular}

\section{Final Discussion}

All prepared RHCl films shows moderate swelling, convenient mucoadhesion strength with increase in residence time that may affect the bioavailability of $\mathrm{RHCl}$.

All the prepared RHCL films formulae were satisfactory in terms of physicochemical properties, swelling index, ex-vivo mucoadhesiveness and in-vitro drug release. Incorporation of the hydrophilic polymer PVP enhanced the drug release and swelling index but significantly decreased the mucoadhesive strength.

Mucoadhesive Buccal film formula F4 (chitosan 1\% w/v, PVP K25 0.07gm, PEG400 1.5gm) was considered to be the optimal prepared film on the basis of its moderate swelling, convenient ex-vivo mucoadhesion time, ex-vivo mucoadhesive strength as well as promising in-vitro drug release pattern. Moreover, it was shown to be stable in human saliva and after one year long term stability study. So, this formula F4 is a promising approach for buccal delivery system of Ropinirole Hydrochloride and will be selected for conducting in- vivo pharmacokinetic study. 


\section{CONCLUSION}

From the above study, one can conclude that chitosan as a mucoadhesive carrier of $\mathrm{RHCl}$ films showed good mucoadhesive properties as well as swelling characteristics. So, it can be successfully used in buccal delivery systems to overcome first-pass metabolism of $\mathrm{RHCl}$ and improve its bioavailability and efficacy.

\section{ABBREVIATIONS}

RHCl; Ropinirole Hydrochloride, PD; Idiopathic Parkinson's disease, RLS; Restless Legs Syndrome, PVP; Polyvinyl pyrrolidone, PEG; Polyethylene glycol, HPLC; high-performance liquid chromatography, fig; figure, conc.; concentration.

\section{ACKNOWLEDGMENTS}

The authors would sincerely like to thank Eva Pharma Pharmaceutical Co., Cairo, Egypt, for providing Ropinirole Hydrochloride as a gift sample. The authors are also grateful to NODCAR for providing the laboratory facilities.

\section{REFRENCES}

Anders R, Merkle HP (1989): Evaluation of laminated mucoadhesive patches for buccal drug delivery. Int J Pharm.;49: 231-240.

Azeem A., Ahmad F. J. , Khar R. K., Talegaonkar S. (2009): Nanocarrier for the Transdermal Delivery of an Antiparkinsonian Drug. AAPS PharmSciTech.; 10(4): 1093-1103.

Boateng JS, Stevens HNE, Eccleston GM, et al. (2009): Development and mechanical characterization of solvent-cast polymeric films as potential drug delivery systems to mucosal surfaces. Drug Dev Ind Pharm.; 35: 986-96.

Bodmeier R, Paeratakul $\boldsymbol{O}$ (1989). Evaluation of drug-containing polymer films prepared from aqueous latexes. Pharm Res.;6:725Y730.

Boothman BR, Spokes EG. (1990): Pharmacokinetic data for Ropinirole. lancet; Vol. 336, No. 8718: p. 814.

Bruschi M L, Freitas O. (2005): Oral bioadhesive drug delivery systems. Drug development and industrial pharmacy; 31: 293-310.

Chandiran, S., Anandakirouchenane (2014): Design and optimization of process and product variable of solid lipid nanoparticle containing Ketoconazole by cold homogenization technique. Int $\mathbf{J}$ of Biological \& Pharmaceutical Research (IJBPR); 5(4): 336-342.

Chandra A., Murtuja S., Chauhan N., Kumar P., Alam S., Prakash S. (2015): Analytical methodology for authentication of Ropinirole using HPLC and FTIR. Int. J. Drug Dev. \& Res.; Vol. 7, Issue 1: 234-239.

Chinchole A.S., B.P., Poul B.N., Panchal C.V., Chavan D.V. (2014): A Review on Stability Guidelines by ICH and USFDA Guidelines for New Formulation and Dosage form. PharmaTutor; Volume 2, Issue 8: 32-53.

Choi HG, Kim CK. (2000): Development of omeprazole buccal adhesive tablets with stability enhancement in human saliva. J Control Release;68:397-404.

Desai KGH, Kumar TMP (2004). Preparation and evaluation of a novel buccal 
adhesive system. AAPS PharmSciTech; 5:article 35.

Dollery C (ed). (1999): Therapeutic drugs. 2nd ed., vol. 2. Edinburgh: Churchill Livingstone; p. R50-R54.

Edsman K, Hagerstrom H. (2005): Pharmaceutical applications of mucoadhesion for the nonoral routes. J Pharm Pharmacol.;57: 3-22.

Eouani C, Piccerelle P, Prinderre P, Bourret E, Joachim J. (2001): In vitro comparative study of buccal mucoadhesive performance of different polymeric films. Eur J Pharm Biopharm; 52: 45-55.

Giradkar KP, Channawar MA, Kajale AD, Sridhar E, Kamble RS, Bakde BV, Chandewar $A V$. (2010): Design, development and in-vitro evaluation of bioadhesive dosage form for buccal route. Int. J. Pharma. Res. Dev.; 2(6): 1-20.

Goud A, Swamy K, Kumar P. (2009): Formulation and evaluation of bioadhesive buccal tablets of simvastatin. Int $\mathbf{J}$ of Advanced Pharmaceutical Sciences (IJAPS) ;1(1): 29-38.

Guo JH, Cooklock M. (1996): The effect of backing materials and multilayered systems on the characteristics of bioadhesive buccal patches. J Pharm Pharmacol.; 48: 255-7.

Haris D, Robinson JR. (1992): Buccal drug delivery via the mucous membrane of oral cavity. J. Pharm. Sci.; 81(1):1-9.

He, P., Davis, S.S., and Ilium, L. (1999): Sustained release chitosan microspher prepared by novel spray drying methods. J. Microencap.; 16: 343-355.

Hobson DE., Pourcher E., Martin WR. (1999): Ropinirole and pramipexole, the new agonists. Can. J. Neurol. Sci.; 26: Suppl.2: S27-S33.

Junginger HE, Hoogstraate JA, Verhoef JC. (1996): Recent advances in buccal drug delivery and absorption: in vitro and in vivo studies. J Control Release; 62: 149-159.

Kaye, C.M. \& Nicholls, B. (2000): Clinical pharmacokinetics of ropinirole. Clin Pharmacokinet.; 39: 243-54.

Koland M, Charyulu RN, Vijayanarayana K, Prabhu P. (2011): In vitro and in vivo evaluation of chitosan buccal films of ondansetron hydrochloride. Int $\mathbf{J}$ Pharm Investig.;1(3): 164-71.

Kumar S., Kumar R., Garg S., Kirar J., Sigroha S. (2014): A Dissolution test apparatus: A comprehensive review. Int J of Pharma Professional's Research (IJPPR); Volume 5, Issue 4: 1142-1149.

Kushida, C.A. (2006): Ropinirole for the treatment of restless legs syndrome. Neuropsychiatr Dis Treat.; 2: 407-19.

Kshirasagar N., Thamada N., Naik V.N., Gopal M.S. (2012): Design and evaluation of chitosan containing mucoadhesive buccal patch of Fluxotine HCL. Int J of Scientific and Research Publications (IJSRP); Volume 2, Issue 6: 1-5. 
Lopez CR, Portero A, Vila-Jato JL, Alonso MJ. (1998): Design and evaluation of chitosan/ethylcellulose mucoadhesive bilayered devices for buccal drug delivery. J Control Release; 55: 143-152.

Luana Periolia, Valeria Ambrogi, Fausta Angelici, Maurizio Ricci, Stefano Giovagnoli, Marinella Capuccella, Carlo Rossi. (2004): Development of mucoadhesive patches for buccal administration of ibuprofen. J Control Release; 99: 73-82.

Mishra R., Amin A. (2009): Formulation Development of Taste-Masked Rapidly Dissolving Films of Cetirizine Hydrochloride. Pharma. Technol.; 33(2): 48-56.

Morales JO1, McConville JT (2010): Manufacture and characterization of mucoadhesive buccal films. Eur J Pharm Biopharm; 77(2): 187-99.

Nafee NA, Boraie NA, Ismail FA, Mortada LM. (2003): Design and characterization of mucoadhesive buccal patches containing Cetylpyridinium chloride. Acta Pharm.; 53: 199-212.

Panchal M.S., Patel H., Bagada A., Vadalia K.R. (2012): Formulation and Evaluation of Mouth Dissolving Film of Ropinirole Hydrochloride by Using Pullulan Polymers. Int J of Pharm Res \& Allied Sci. (IJPRAS); Volume 1, issue 3: 6072.

Patel VM, Prajapati BG, Patel MM. (2007): Formulation, evaluation and comparison of bilayered and multilayered mucoadhesive buccal devices of propranolol hydrochloride. AAPS PharmSciTech.; 8(2): Article 45: E1-E8.

Raghavendra RIO N.G. , Suryaka V.B. (2011): Design and development of mucoadhesive drug delivery system of Montelukast sodium. Int J of Research in Ayurveda \& Pharmcy (IJRAP); 2(2), 491-497.

Rathbone M. J., Drummond B. K., Tucker I. G. (1994). The oral cavity as a site for systemic drug delivery. Advanced Drug Delivery Reviews, Volume 13, Issues 1-2: 1-22.

Singh A.R., Singh A., Madhav N.V. S. (2012). Nasal cavity: A Promising Transmucosal Platform For Drug Delivery And Research Approaches From Nasal To Brain Targeting. Journal of Drug Delivery \& Therapeutics; 2: 22-33.

Tejada G., Barrera M. G., Piccirilli G. N., Sortino M., Frattini A.,. Salomón C. J, Lamas M. C., Darío Leonardi (2017). Development and Evaluation of Buccal Films Based on Chitosan for the Potential Treatment of Oral Candidiasis. AAPS PharmSciTech; 18, No. 4: 936-946. 


\section{صياغة و توصيف أغشية الكيتوزان ذات خاصية الالتصاق بالغثاء المخاطى للفم التى تحتوى

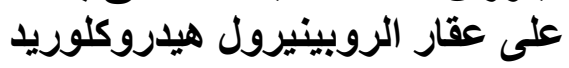 \\ لل السادة الاكاترة \\ نادية أحمد مرسى' ، أحمد حسن الثافعى'، منال ياسين حمزة' ، رحاب محمد محمد الحديدى' \\ مسن}

ا قسم الصيدلانيات و الصيدلة الصناعية ـ كلية الصيدلة ـ جامعة القاهرة

r الهيئة القومية للرقابة و البحوث الدو ائية ـ القاهرة

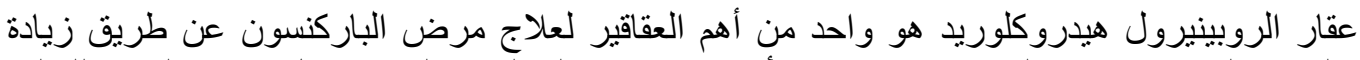

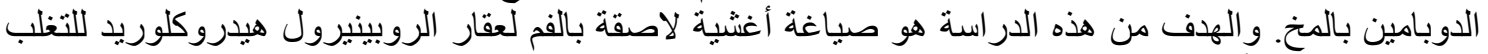

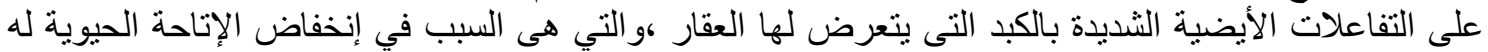

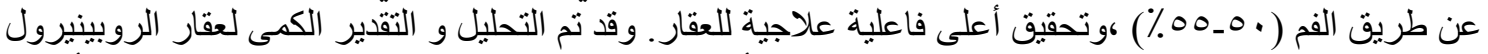

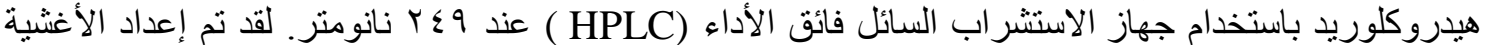

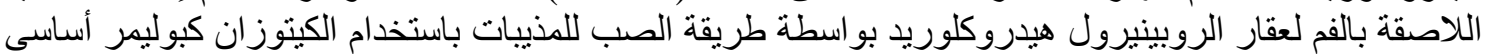

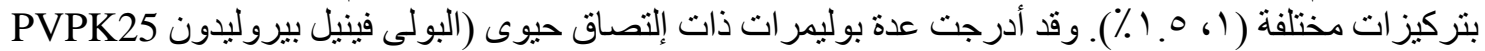
و PVPK30 في الأغشية لتعديل معدل إنطلاق عقار الروبينيرول هيدروكلوريد الته من الصياغات المعدة.

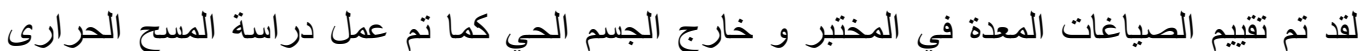

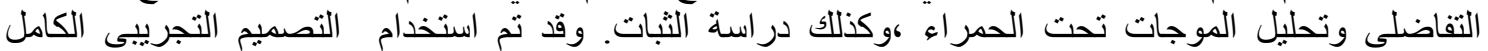

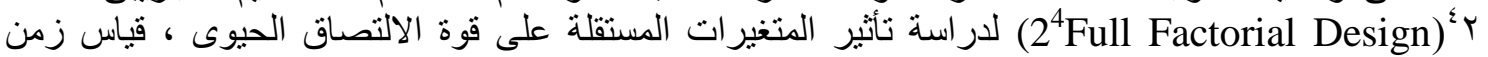
الإلتصاق ، معدل إنطلاق العقار من الأغثية المحضرة .

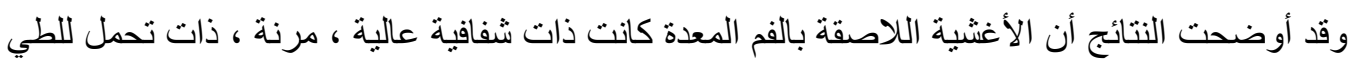

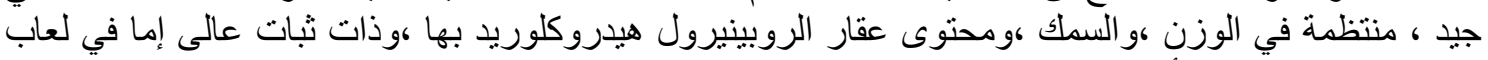

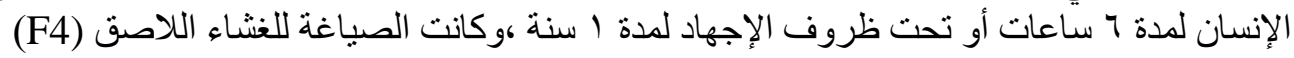
هى الصياغة المثلى ذات أعلى نسبة إنطلاق لعقار الروبينيرول (PEG400, PVPK25, 1\% Chitosan)

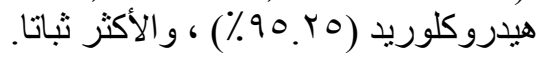

